\title{
Percepción de docentes y estudiantes acerca de la actividad educativa en la escuela de enfermería de la UNMSM y propuesta co-participativa de planes de mejora
}

\author{
R. Cornejo, M. Carhuapoma, G. Samillán, M. Vera, J. Cuéllar, R. Casquero
}

Departamento Académico Profesional de Enfermería, Facultad de Medicina, UNMSM

Objetivos: Caracterizar la actividad académica, el cumplimiento de las obligaciones, programa, metodología, materiales, actitud del docente, evaluación, prácticas, satisfacción. Establecer las coincidencias y divergencias de la actividad educativa en Enfermería. Y comprometer a los involucrados a participar en el diseño de propuestas.

Diseño: Método descriptivo, transversal, cuantitativo, complementado con técnicas cualitativas.

Institución: Departamento Académico Profesional de Enfermería, Facultad de Medicina, UNMSM.

Participantes: Estudiantes y docentes.

Intervenciones: Se efectuó el estudio en 135 estudiantes y 27 docentes (30\% del universo de docentes y estudiantes). La escala fue de 1 a 5 , siendo 1 definitivamente negativa y 5 definitivamente positiva.

Principales medidas de resultados: Calidad de la actividad académica.

Resultados: En estudiantes fue 3,57 y en docentes 3,70, indicando que estamos cercanos al punto medio y lejos de calidad 'definitivamente positiva'. El menor valor fue la dimensión 'prácticas', con un valor de 2,74, con 'opinión negativa'. El valor más alto estuvo en 'Programa de Enseñanza', con 3,91, cerca de 'opinión positiva'.

Conclusiones: Hubo dos categorías de resultados, actitud docente y aptitud docente, señalando que los docentes se mantienen 'sin interés', 'poco comprometidos' con su labor docente. Falta mejorar la planificación de clases, metodología, supervisión y evaluación; un mejor uso del tiempo, para no afectar la 'práctica clínica o comunitaria'.

Palabras clave: Enfermería, actividad educativa, estudiantes, docentes. 